\title{
Rare homozygous mutation in TUBB8 associated with oocyte maturation defect- 2 in a consanguineous mating family
}

\author{
Qiong Xing ${ }^{1,2,3 \dagger}$, Ruyi Wang ${ }^{4,5+}$, Beili Chen ${ }^{1,2,3}$, Lin Li ${ }^{6}$, Hong Pan ${ }^{4,5}$, Tengyan Li ${ }^{5}$, Xu Ma ${ }^{4,5^{*}}$, Yunxia Cao ${ }^{1,2,3^{*}}$ and
} Binbin Wang ${ }^{4,5^{*}}$

\begin{abstract}
Purpose: Variations in many genes may lead to the occurrence of oocyte maturation defects. To investigate the genetic basis of oocyte maturation defects, we performed clinical and genetic analysis of a pedigree.

Methods: The proband with oocyte maturation defect-2 receiving ovulation induction therapy and her parents were selected for clinical detection, whole exome sequencing and Sanger sequencing. One unrelated healthy woman received ovulation induction therapy as control. Mutations were assessed after frequency screening of public exome databases. Then homozygous variants shared by the proband and her parents were selected.
\end{abstract}

Results: Arrest of oocytes maturation was observed. A new missense mutation in TUBB8 (TUBB8: NM_177,987: exon 2: c. (161T: p. A54V) was identified, which was shown to be rare compared with public databases. The variant was highly conserved among primates, and was suggested to be deleterious by online software prediction.

Conclusions: The homozygote of this variant (TUBB8: NM_ 177,987: exon 2:c.C161T: p.A54V) might affect spindle assembly, cause arrest of oocyte maturation and lead to oocyte maturation defect-2.

Keywords: Oocyte maturation defect-2, TUBB8, Whole exome sequencing, Missense mutation, Parthenogenesis

\section{Introduction}

In the fetal ovary, oocytes pause at prophase I. When puberty starts, the maturation process of oocytes begins, and oocytes resume meiosis with a surge of luteinizing hormone. Germinal vesicle (GV) breakdown, spindle assembly, chromosomal migration, asymmetric division, and extrusion of the first polar body occur in turn. The oocytes arrest at metaphase II (MII) until fertilization [1, 2]. Primary infertility or failure of in vitro fertilization

\footnotetext{
*Correspondence: genetic88@126.com; caoyunxia6@126.com; wbbahu@163.com

Qiong Xing and Ruyi Wang consider as joint First Authors

${ }^{4}$ Graduate School of Peking Union Medical College, Beijing, China

${ }^{1}$ Reproductive Medicine Center, Department of Obstetrics and Gynecology,

the First Affiliated Hospital of Anhui Medical University, 218 Jixi Road,

Shushan, Hefei 230022, China

Full list of author information is available at the end of the article
}

(IVF) were the clinical manifestation of oocyte maturation defects (OOMDs). Failure of GV breakdown, absence of the first polar body, and failure to progress beyond MII could result in arrest of oocyte maturation [3].

Previous researchers have found many genes related to OOMDs, including ZP1, ZP2, ZP3, WEE2, PATL2, and $T U B B 8$. Mutations in $Z P 1, Z P 2$, and $Z P 3$ could result in oocyte maturation defect-1 (OOMD1), OOMD6, and OOMD3, respectively. The absence of the zona pellucida was caused by mutations in these three genes and this resulted in degeneration of oocytes and "empty follicle syndrome" during IVF treatment [4-6]. The mutations in WEE2 resulted in OOMD5, which was characterized by arrest of oocyte maturation at MII and inability to form pronuclei after fertilization [7]. While the mutations in

C C The Author(s). 2020 Open Access This article is licensed under a Creative Commons Attribution 4.0 International License, which permits use, sharing, adaptation, distribution and reproduction in any medium or format, as long as you give appropriate credit to the original author(s) and the source, provide a link to the Creative Commons licence, and indicate if changes were made. The images or other third party material in this article are included in the article's Creative Commons licence, unless indicated otherwise in a credit line to the material. If material is not included in the article's Creative Commons licence and your intended use is not permitted by statutory regulation or exceeds the permitted use, you will need to obtain permission directly from the copyright holder. To view a copy of this licence, visit http://creativecommons.org/licenses/by/4.0/ The Creative Commons Public Domain Dedication waiver (http://creativecommons.org/publicdomain/zero/1.0/) applies to the data made available in this article, unless otherwise stated in a credit line to the data. 
PATL2 resulted in OOMD4, which was characterized by fertilization failure and early embryonic arrest [8].

Feng et al. discovered that OOMD2 was caused by mutations in the TUBB8 gene which located at chromosome 10. OOMD2 was characterized by spindle damage in metaphase I (MI) or MII, resulting in fertilization failure $[9,10]$.

To study the genetic basis of oocyte maturation defects, we found a consanguineous mating pedigree and searched for the pathogenic gene of this family by whole exome sequencing (WES). We targeted the TUBB8 gene.

\section{Material and methods \\ Participants}

The family of the proband and an unrelated healthy woman were recruited from the Reproductive Center of the First Affiliated Hospital of Anhui Medical University. The clinical features of the unrelated woman were normal, and most of her oocytes retrieved from body were mature. The proband and her parents (Fig. 1) underwent genetic testing and analysis (Fig. 2). We collected peripheral blood samples from the three individuals. The study protocol was approved by the Ethics Committee of the National Research Institute for Family Planning, and written informed consent was obtained from all participants.

The proband of a consanguineous mating family was affected by OOMD2 with unique clinical characteristics.
The proband (IV-1) was a woman with primary infertility whose oocytes showed developmental disorders during induction of clinical ovulation. Her parents were not affected and they were cousins (Fig. 1).

The proband, who was 31 years old, has not got pregnant for 5 years after marriage. She was $163 \mathrm{~cm}$ height and weighed $50 \mathrm{~kg}$. Clinical features, routine test results, endocrine test results, immunological test results, and a hysteroscopy examination were all normal. The chromosome examination showed a normal karyotype 46, XX, while her husband showed 46, XY. The proband's characteristics are shown in Table 1.

\section{Evaluation of oocyte phenotypes}

The proband received 3 cycles of controlled ovarian stimulation (COS) during her IVF treatment (Table 1). The first cycle was treated with a long regimen, the second cycle was treated with mild-stimulation protocol and the third cycle was treated with mild-stimulation and in vitro maturation protocols (shown in Table 2). During the whole process of 3 cycles of COS, development of follicles' size and hormone level were all normal.

Transvaginal oocyte retrieval was performed $35-36 \mathrm{~h}$ following human chorionic gonadotrophin (HCG) trigger. Oocytes were obtained from the patient. The morphology of oocytes was observed by light microscopy (Figs. 3 and 4).

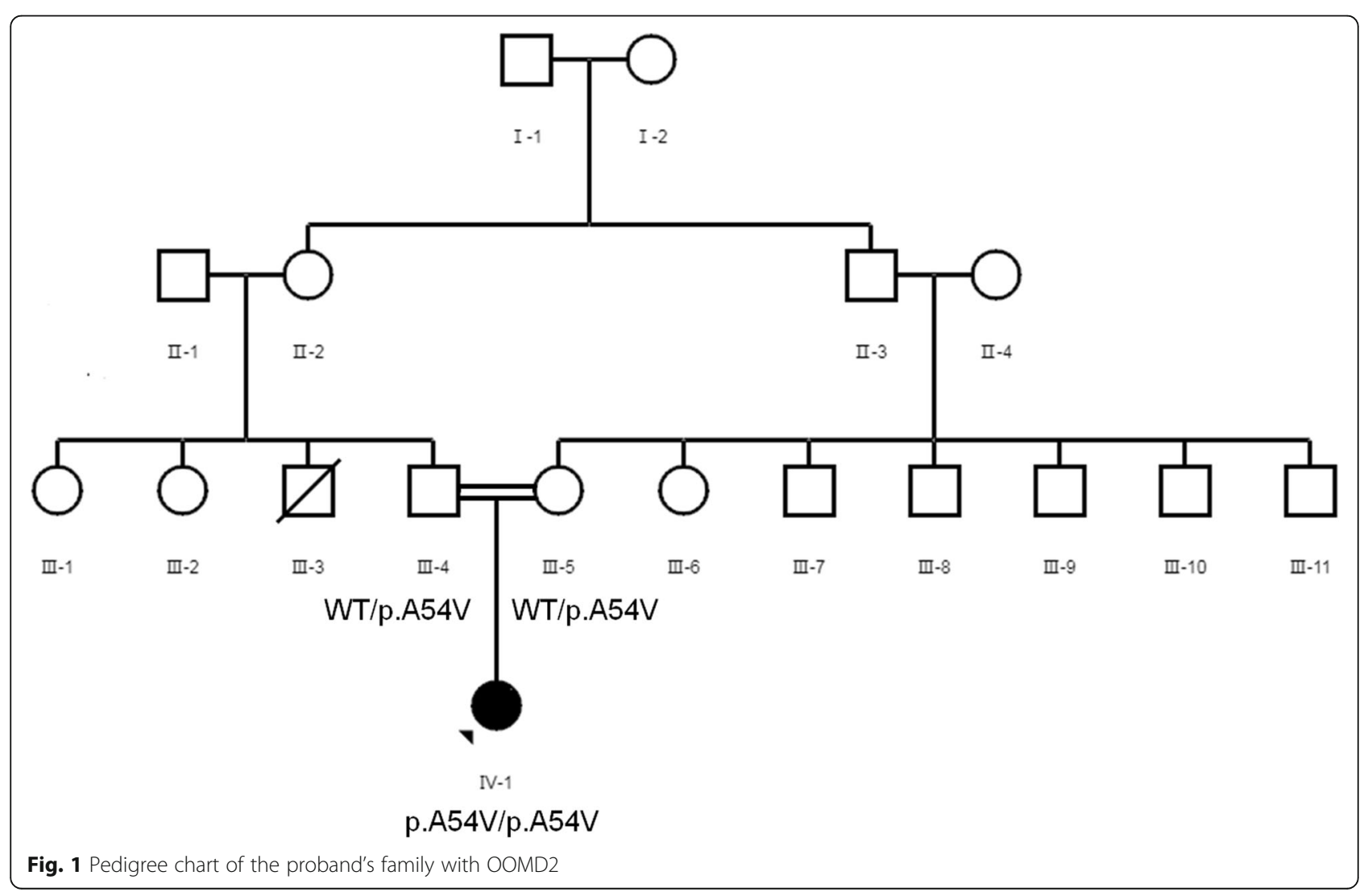




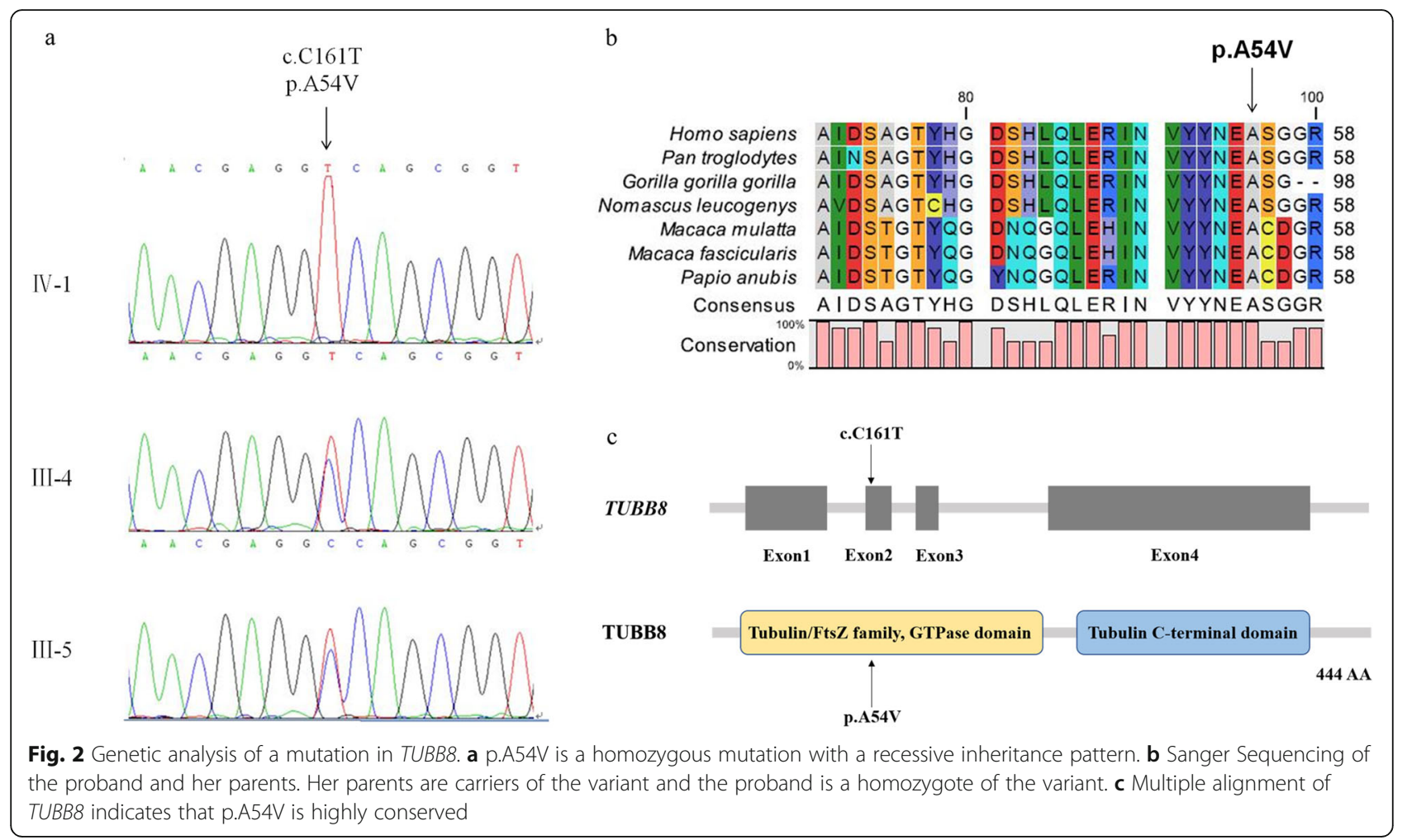

Although all these immature oocytes were cultured in in vitro mature (IVM) medium for $24 \mathrm{~h}$, they were still immature. So we couldn't perform fertilization for her. All the cycles were cancelled.

\section{WES and mutation screening}

Genomic DNA was extracted from peripheral venous blood using the QIAamp DNA Blood Mini Kit (Qiagen, Hilden, Germany). All exomes were captured with the SureSelect Human All Exon V5 kit (Agilent, Santa Clara, CA) and then sequenced on the Illumina HiSeq2000 sequencer (Illumina, San Diego, CA). Reads were mapped to the human reference genome (hg19) using BWA - 0.7.10 (Burrows-Wheeler Alignment Tool). Variants including single nucleotide polymorphisms and indels were called by GATK 3.v4 (Genome Analysis Toolkit) and annotated with SnpEff _v4.1. Candidate genes were analyzed on the basis of sequencing results, the family tree, and public databases.

\section{Validation with sanger sequencing}

TUBB 8 was sequenced by Sanger sequencing in three subjects using the primer pair. The sequences of the primer pair were as follows:

Forward primer: $5^{\prime}$-CCCCAACGTGGAAAGGACC3';

Reverse primer: 5'-CCCATTCTCAGGAAAGGC AGTAG-3'.

\section{Online prediction}

Public databases, including online forecasting programs, such as 1000 Genomes, ESP6500si, and ExAC Asian population, were used to obtain the frequency of variants. Online prediction programs, including SIFT, Mutation Taster, PolyPhen-2, and PROVEAN, were used to predict the effect of missense mutations on proteins. CLC Sequence Viewer 8 software was used for conservation analysis.

Table 1 Basal characteristics

\begin{tabular}{lcccccccccc}
\hline $\begin{array}{l}\text { Age } \\
\text { (years) }\end{array}$ & $\begin{array}{l}\text { Infertility duration } \\
\text { (years) }\end{array}$ & $\mathrm{BMI}\left(\mathrm{kg} / \mathrm{m}^{2}\right)$ & $\mathrm{E} 2(\mathrm{pmol} / \mathrm{L})$ & $\mathrm{FSH}(\mathrm{IU} / \mathrm{L})$ & $\mathrm{LH}(\mathrm{IU} / \mathrm{L})$ & $\mathrm{AMH}(\mathrm{ng} / \mathrm{ml})$ & $\mathrm{PRL}(\mathrm{ng} / \mathrm{ml})$ & $\mathrm{T}(\mathrm{nmol} / \mathrm{l})$ & $\mathrm{P}(\mathrm{nmol} / \mathrm{l})$ & $\mathrm{TSH}(\mathrm{mlU} / \mathrm{L})$ \\
\hline 31 & 5 & 18.8 & 153 & 6.27 & 3.69 & 3.6 & 20.13 & 2.2 & 1.69 & 2.47 \\
\hline
\end{tabular}

BMI Body mass index (normal range: $18.5-23.9 \mathrm{~kg} / \mathrm{m}^{2}$ ), E2 Estradiol (normal range: $40-253 \mathrm{pmol} / \mathrm{L}$ ), FSH Follicle stimulating hormone (normal range: $2.5-10.2 \mathrm{IU} / \mathrm{L}$ ), LH Luteinizing hormone (normal range: 1.9-12.5 IU/L), AMH Anti-Müllerian hormone (normal range: 0.24-11.78 IU/L), PRL Prolactin (normal range: 5.18-26.53 ng/ $\mathrm{ml}$ ), $P$ Progesterone (normal range: $0.6-1.9 \mathrm{nmol} / \mathrm{l}), T$ Testosterone (normal range: $0.9-2.9 \mathrm{nmol} / \mathrm{l})$, TSH Thyrotropin (normal range: $0.49-4.67 \mathrm{mIU} / \mathrm{L}$ ) 
Table 2 Clinical characteristics of 3 cycles

\begin{tabular}{|c|c|c|c|c|c|c|}
\hline $\begin{array}{l}\text { Cycle } \\
\text { number }\end{array}$ & $\begin{array}{l}\text { Date/Menstrual } \\
\text { cycle }\end{array}$ & Medicine & $\begin{array}{l}\text { Follicles of right ovary } \\
(\mathrm{mm}(\mathrm{N}))\end{array}$ & $\begin{array}{l}\text { Follicles of left } \\
\text { ovary }(m m(N))\end{array}$ & $\begin{array}{l}\text { Total Number of } \\
\text { oocyte retrieved }\end{array}$ & $\begin{array}{l}\text { Stage of Oocyte }(N) \text { after } \\
24-36 \mathrm{~h} \text { of culture in vitro }\end{array}$ \\
\hline \multirow[t]{6}{*}{1} & & & & & 23 & $\mathrm{MI}(22)+\mathrm{GV}(1)$ \\
\hline & 2017.10.25/D18 & GnRHa (mg):0.9 & & & & \\
\hline & 2017.11.8/D5 & $\mathrm{rFSH}(\mathrm{U}): 150^{*} 5 \mathrm{~d}$ & $2 * 2(3)$ & $2 * 2(4)$ & & \\
\hline & 2017.11.13/D10 & $\mathrm{rFSH}(U): 150^{*} 4 \mathrm{~d}$ & $8^{*} 8(3), 6^{*} 6(3)$ & $10^{*} 9(2), 8^{*} 7(1), 7^{*} 5(3)$ & & \\
\hline & 2017.11.17/D14 & $\mathrm{rFSH}(U): 150^{*} 3 \mathrm{~d}$ & $\begin{array}{l}15^{*} 14(1), 14^{*} 14(1) \\
12^{*} 11(4)\end{array}$ & $\begin{array}{l}15^{*} 15(1), 15^{*} 13(2), 16^{*} 12(1), \\
14^{*} 14(2), 14^{*} 10(1), 12^{*} 12(2)\end{array}$ & & \\
\hline & 2017.11.20/D17 & rHCG (ug): 250 & $21 * 21(1)$ & $\begin{array}{l}22^{*} 19(1), 21^{*} 20(2), 19^{*} 17(2), \\
19^{*} 16(2), 18^{*} 17(1)\end{array}$ & & \\
\hline \multirow[t]{6}{*}{2} & & & & & 21 & $\begin{array}{l}\mathrm{Ml}(12)+\mathrm{GV}(2)++ \\
\text { degenerate oocytes (7) }\end{array}$ \\
\hline & 2018.3.19/D3 & $\begin{array}{l}\mathrm{HMG}(\mathrm{U}): 225^{*} 5 \mathrm{~d} \\
\text { Clomiphene } \\
\text { citrate (mg): } 100 * 5 \mathrm{~d}\end{array}$ & $5-6(3-6)$ & $6-7(3-6)$ & & \\
\hline & 2018.3.24/D8 & $\begin{array}{l}\text { HMG(U): } 225 \\
\text { Clomiphene citrate } \\
\text { (mg): } 100\end{array}$ & $\begin{array}{l}16^{*} 13(1), 14^{*} 13(1) \\
13^{*} 12(1)\end{array}$ & $15^{*} 11(2)$ & & \\
\hline & 2018.3.25/D9 & $\begin{array}{l}\mathrm{HMG}(\mathrm{U}): 225^{*} 2 \mathrm{~d} \\
\text { Clomiphene citrate } \\
\text { (mg): } 100^{*} 2 \mathrm{~d} \\
\text { Ganirelix (mg): } 0.25^{*} 2 \mathrm{~d}\end{array}$ & & & & \\
\hline & 2018.3.27/D11 & $\begin{array}{l}\text { HMG(U): } 225 \\
\text { Ganirelix (mg): } 0.25\end{array}$ & $\begin{array}{l}23^{*} 21(1), 20^{*} 17(1) \\
18^{*} 15(2), 17^{*} 17(2) \\
17^{*} 15(2)\end{array}$ & $20 * 17(2), 18^{*} 14(2), 17^{*} 12(2)$ & & \\
\hline & 2018.3.28/D12 & $\begin{array}{l}\text { Ganirelix (mg): } 0.25 \\
\text { HCG (IU): } 8000\end{array}$ & $\begin{array}{l}22^{*} 22(1), 21 * 20(1) \\
20^{*} 20(3), 19^{*} 19(2) \\
18^{*} 18(2)\end{array}$ & $\begin{array}{l}23^{*} 17(1), 22^{*} 20(1), 18^{*} 18(1) \\
17^{*} 17(1)\end{array}$ & & \\
\hline \multirow[t]{4}{*}{3} & & & & & 12 & $\begin{array}{l}\mathrm{MI}(7)+\mathrm{GV}(3)+ \\
\text { degenerate oocytes(2) }\end{array}$ \\
\hline & 2018.9.18/D3 & $\mathrm{HMG}(U): 225^{*} 4 \mathrm{~d}$ & $3-4(6)$ & $3-4(7)$ & & \\
\hline & 2018.9.22/D7 & $\mathrm{HMG}(U): 225^{*} 2 \mathrm{~d}$ & $\begin{array}{l}8^{*} 8(1), 6^{*} 5(1), 5^{*} 5(1) \\
4^{*} 4(1), 4^{*} 3(1)\end{array}$ & $10^{*} 7(1), 9^{*} 9(1), 9^{*} 7(1), 8^{*} 8(1)$ & & \\
\hline & 2018.9.24/D9 & HCG(U): 10000 & $\begin{array}{l}13^{*} 12(1), 8^{*} 8(2), 7^{*} 7(1) \\
5^{*} 5(4)\end{array}$ & $\begin{array}{l}13^{*} 13(1), 13^{*} 12(1), 12^{*} 12(1) \\
11^{*} 11(1), 10^{*} 10(2), 9^{*} 9(1)\end{array}$ & & \\
\hline
\end{tabular}

$D$ Day number of menstrual cycle, $d$ Days of continuous medication, $N$ Number, $r F S H$ recombinant follicle stimulating hormone (Gonal-F, merck Serono, Switzerland), rHCG recombinant human chorionic gonadotrophin (Ovidrel, merck Serono, Germany), HMG human menopausal gonadotropin (Lebaode, Livzon, Zhuhai), HCG human chorionic gonadotrophin (Livzon, Zhuhai), GnRHa (Diphereline, Ipsen, France), Ganirelix (Orgalutran, merck sharp organon, USA), Clomiphene citrate (Clomifene Citrate Tablets, Hengshan, shanghai)

\section{Results}

\section{Phenotypes of oocytes}

Three cycles of ovulation induction therapy (controlled ovarian stimulation) were carried out. During each of the 3 cycles of treatment, oocytes were retrieved from the patient and all oocytes were observed at the GV stage and MI stage under a microscope (Fig. 3). While, after a cycle of ovulation induction treatment, most oocytes of the healthy individual were at the MII stage (Fig. 4). The oocytes retrieved from the patient were all immature at that time, and were not developed to the MII stage after 24-36 $\mathrm{h}$ culture in vitro (Table 2 ).

In the first cycle, 24 immature oocytes were obtained after receiving treatment. After $24 \mathrm{~h}$ of culture, all oocytes were still arrested at the GV stage and MI stage.
In the second cycle, 21 oocytes were obtained after receiving treatment. After $24 \mathrm{~h}$ of culture in vitro, 14 oocytes were arrested at the GV stage and MI stage, and 7 oocytes degenerated.

In the third cycle, 12 oocytes were obtained after receiving treatment. After $24-36 \mathrm{~h}$ of culture, 14 oocytes were arrested at the GV stage and MI stage, and 7 oocytes degenerated.

\section{WES results}

DNA samples from the proband and her parents were used for WES. We selected mutations shared by the three sequenced subjects, and focused on nonsynonymous mutations, including nonsense, missense, splice-site, and frameshift mutations. We discarded all variants with a frequency of $>0.1 \%$ in public databases 


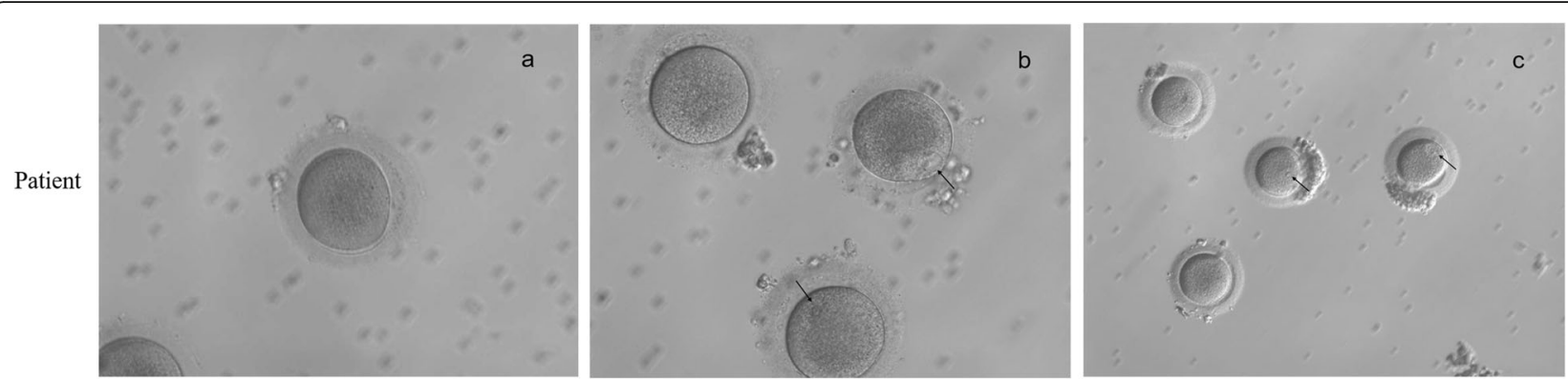

Fig. 3 Morphology of oocytes that were retrieved from the patient with a TUBB8 mutation (p.A54V). a One MI oocyte from the patient. b One GV oocyte and two Ml oocytes from the patient. c Two GV oocytes and two Ml oocytes from the patient. Black arrows indicate the nucleus of the oocyte and hollow arrows indicate the first polar body

(1000 Genomes, ESP6500si, and ExAC Asian population). Because the parents of the proband were cousins and neither of them was affected, we speculated that the inheritance pattern of this mutation was recessive. Therefore, we selected homozygous mutations in the proband. These homozygous mutations included TUBB8 and NCOA2 (Table 3). Furthermore, we found some genes related to OOMDs in public databases, including OMIM [11], PubMed [12], GO [13], and MGI databases [14]. In the MGI database and GO database, NCOA2 plays an important role in chromatin binding activity; RNA polymerase II regulatory region sequence-specific DNA binding activity; and thyroid hormone receptor coactivator activity. NCOA2 is associated with acute myeloid leukemia. In the PubMed database and OMIM database, NCOA2 has not been reported to be related to oocyte development. Eventually, the TUBB8 gene was targeted (Table 3).

We identified a TUBB8 C-T variant (TUBB8: NM_ 177,987: exon 2: c.C161T: p.A54V) at 161th base. This resulted in an amino acid change from alanine to valine at the 54th residue (Table 3).

\section{Validation with sanger sequencing}

$T U B B 8$ was sequenced by Sanger sequencing in the three subjects to exclude false positive results from WES. We found that the parents of the proband were carriers of the TUBB8 variant, and the proband was a homozygote of the variant (Fig. 2).

\section{Online analysis and prediction}

This variant was not found in 1000 Genomes, with a frequency of $<0.1 \%$ in ESP6500si and ExAC Asian population. Online programs, including MutationTaster and SIFT, predicted this variant to damage protein function. Polyphen-2 and PROVEAN predicted that this variant was benign (Table 3). The TUBB8 variant was also found to be highly conserved among primates (Fig. 2).

\section{Discussion}

OOMDs can be classified into six subtypes, and different pathogenic genes lead to different genetic and clinical characteristics of different subtypes [4, 5, 7-10, 15]. Mutation of the TUBB8 gene leads to OOMD2. Inheritance of OOMD2 can be either autosomal dominant or autosomal recessive. Female primary infertility was the clinical trait of OOMD2. The corresponding phenotype includes arrest at MI or MII of oocytes, fertilization failure, stagnation of early embryonic development, and failure of embryo implantation [16]. Expression of TUBB8 protein is unique to oocytes and early embryos. Thus, male carriers of the TUBB8 mutation are fertile [9].

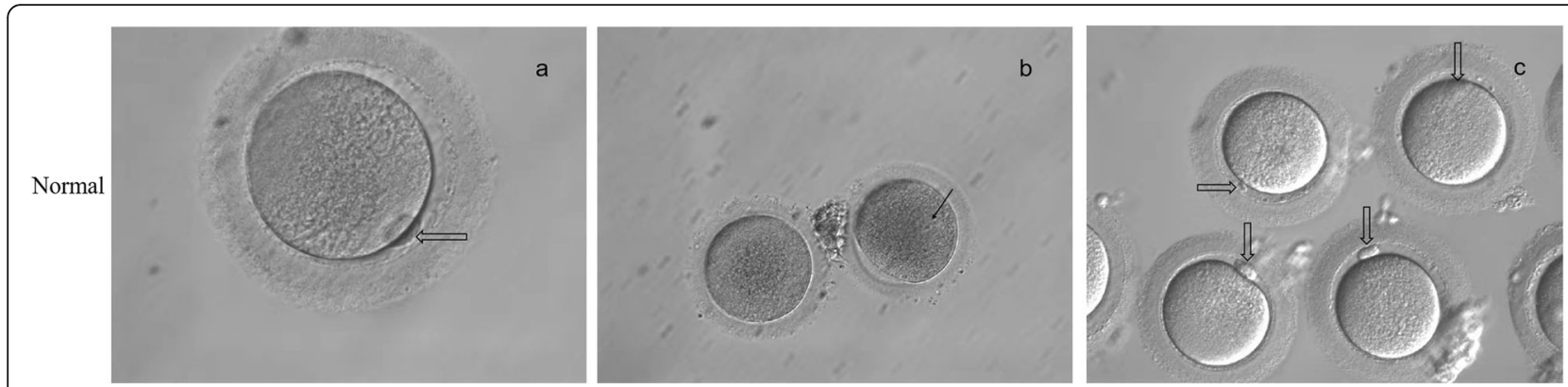

Fig. 4 Morphology of oocytes that were retrieved from a healthy individual. a One MII oocyte from a healthy individual. b One MI oocyte and one GV oocyte from a healthy individual. c Four MII oocytes from a healthy individual. Black arrows indicate the nucleus of the oocyte and hollow arrows indicate the first polar body 
Table 3 Candidate variants with whole exome sequencing

\begin{tabular}{|c|c|c|c|c|c|c|c|c|c|}
\hline \multirow[t]{2}{*}{ Gene } & \multirow{2}{*}{$\begin{array}{l}\text { Chromosome } \\
\text { Position }\end{array}$} & \multirow[t]{2}{*}{ Variant } & \multirow[t]{2}{*}{$1000 \mathrm{G}(\%)$} & \multirow[t]{2}{*}{ ESP6500si(\%) } & \multirow{2}{*}{$\begin{array}{l}\text { ExAC } \\
\operatorname{EAS}(\%)\end{array}$} & \multicolumn{4}{|c|}{ Online Prediction } \\
\hline & & & & & & SIFT & MutationTaster & PolyPhen2 & PROVEAN \\
\hline TUBB8 & Chr10:48809 & NM_177,987:c.C161T:p.A54V & 0 & 0.01 & 0.02 & $\mathrm{D}$ & $\mathrm{D}$ & B & N \\
\hline $\mathrm{NCOA} 2$ & Chr8:70123918 & NM_006540:c.C4259T:p.P1420L & 0 & 0 & 0 & D & $\mathrm{D}$ & $\mathrm{D}$ & $\mathrm{D}$ \\
\hline
\end{tabular}

$B$ predicted to be benign, $D$ predicted to be deleterious, $N$ predicted to be neutral, EXAC_EAS Frequency of corresponding variants in the ExAC Asian population

TUBB8 is one of the microtubulin family genes. There are nine types of beta-tubulin in mammals. Beta-tubulin can be distinguished mainly by a change in the C-terminal domain affecting specific cell functions [17]. In early embryos, this gene occupies almost all of the expressed beta-tubulin. Microtubules are dynamic polymers composed of alpha/beta-tubulin isodimers [18]. TUBB8 protein has two domains, including a GTPase domain and C-terminal domain.

In previous studies, researchers have found several inheritance patterns of TUBB8 mutations, including heterozygous mutations $[6,9,10,16,19-21]$, homozygous mutations $[6,10,16,22]$, compound heterozygous mutations [16, 21], and homozygous deletions [16]. These mutations affect folding and assembly of alpha/ beta-tubulin isodimers. This process changes the dynamics of microtubules in vivo, and results in disastrous spindle assembly defects and arrest of oocyte maturation in human oocytes. Some TUBB8 variants of dominant inheritance have significant negative effects, which interfere with microtubule behavior and meiotic spindle assembly of oocytes, leading to arrest of oocyte maturation and female infertility [19].

We found a consanguineous mating family in which the proband suffered from primary infertility. After a cycle of ovulation induction treatment, most oocytes of the healthy individual were at the MII stage, while oocytes of the patient were at the GV stage or MI stage. After a period of culture in vitro, the oocytes remained immature. We considered that there might be some genetic factors leading to arrest of oocyte development.

We identified a TUBB8 variant (TUBB8: NM_177,987: exon 2: c.C161T: p.A54V) from a family by WES. Because the parents of the proband were cousins and neither of them was affected, we speculated that the inheritance pattern of this mutation was recessive (Fig. 1).

The variant that we found was located in exon 2, and the affected residue(p.A54) was located in the GTPase domain (Fig. 2a). And we referred to a previous study of missense mutations (p.P70L and p.C12Y) located in $\beta$ tubulin subunit in the GTPase domain of which their inheritance patterns were also recessive, the two affected residues may influenced folding or protein stability [6]. Thus, the affected residues that we found (p. A54) may influence folding/protein stability. And TUBB8 is an important component of oocyte spindle [9], so the homozygote of the variant that we found might affect spindle assembly, which will result in arrest of oocyte maturation. Heterozygous missense mutations cause arrest of oocyte maturation through dominant-negative effects. In this study, however, the patient with homozygous p.A54V TUBB8 mutations suffered from OOMD2, while her parents with the heterozygous p.A54V missense mutations were fertile. This finding suggested that heterozygous p.A54V mutations could not affect female fertility. Thus, p.A54V has a haploinsufficiency effect than a dominant-negative effect.

We reviewed variants in TUBB8 that have reported previously (Supplementary Table 1). We found that the inheritance pattern of p.E27_A33del located in exon 2 was recessive [10]. While our newly discovered p.A54V was located in exon 2 and the inheritance pattern was also recessive.

The discovery of this variant started with investigation of the pedigree of OOMD (Fig. 1). Because the proband's parents were cousins and neither of them was affected, we speculated that the inheritance pattern of this mutation was recessive. Therefore, we selected homozygous mutations from the proband. This helped us to quickly identify this variant of TUBB8. Consanguineous mating families are useful for studying mechanisms of genetic diseases without human intervention.

This study elucidated the cause of oocyte maturation defects. The results confirmed that mutations of TUBB8 contributed genetically to OOMD2 and expanded the mutation spectrum of $T U B B 8$.

\section{Conclusions}

A rare variant of TUBB8 (TUBB8: NM_177,987: exon 2: c.C161T: p.A54V) was found in a Chinese consanguineous mating family with OOMD2 by WES and Sanger sequencing. The homozygote of this variant might affect spindle assembly, which will cause arrest of oocyte maturation and lead to primary infertility. The variant (TUBB8: NM_177,987: exon 2:c.C161T: p.A54V) in the public database is rare, and this site is highly conserved among primates. Our findings confirmed that mutations of TUBB 8 contributed genetically to OOMD2. Our findings expanded the mutation spectrum of TUBB8 causing OOMD2 and provided a basis for targeted therapy in the future. 


\section{Supplementary information}

Supplementary information accompanies this paper at https://doi.org/10. 1186/s13048-020-00637-4.

Additional file 1 : Supplementary Table 1. Variants of TUBB8 reported in previous studies.

\section{Acknowledgements}

We would like to acknowledge the patient and her parents to support our research

\section{Authors' contributions}

The first draft of the manuscript was written by Qiong Xing and Ruyi Wang; the study conception and design were performed by Binbin Wang, Xu Ma and Yunxia Cao, material preparation was performed by Beili Chen and Tengyan Li; data collection and analysis were performed by Lin Li and Hong Pan. The author(s) read and approved the final manuscript

\section{Funding}

This project was supported by the CAMS Innovation Fund for Medica Sciences (2018-I2M-1-004) and the CAMS Fund for Excellent Young Medical Talents (2018RC310024).

\section{Availability of data and materials} Not applicable.

\section{Ethics approval and consent to participate}

Our research was approved by the Ethics Committee for Clinical Medical Research of The First Affiliated Hospital of Anhui Medical University. All participants signed informed consent forms during blood sample collection and analysis.

\section{Consent for publication}

Not applicable.

\section{Competing interests}

All authors declare no conflict of interest.

\section{Author details}

${ }^{1}$ Reproductive Medicine Center, Department of Obstetrics and Gynecology, the First Affiliated Hospital of Anhui Medical University, 218 Jixi Road Shushan, Hefei 230022, China. ${ }^{2}$ Anhui Province Key Laboratory of Reproductive Health and Genetics, Biopreservation and Artificial Organs, Hefei, China. ${ }^{3}$ Anhui Provincial Engineering Research Center, Anhui Medical University, Hefei, P.R. China. ${ }^{4}$ Graduate School of Peking Union Medical College, Beijing, China. ${ }^{5}$ Center for Genetics, National Research Institute for Family Planning, 12 Dahuisi Road, Haidian, Beijing 100081, China. ${ }^{6}$ Central Laboratory, Beijing Obstetrics and Gynecology Hospital, Capital Medical University, Yaojiayuan Road 251, Chaoyang, Beijing 100026, China.

Received: 31 January 2020 Accepted: 23 March 2020

Published online: 21 April 2020

\section{References}

1. Li R, Albertini DF. The road to maturation: somatic cell interaction and selforganization of the mammalian oocyte. Nat Rev Mol Cell Biol. 2013;14(3): 141-52. https://doi.org/10.1038/nrm3531.

2. Coticchio G, Dal Canto M, Mignini Renzini M, Guglielmo MC, Brambillasca F, Turchi D, Novara PV, Fadini R. Oocyte maturation: gamete-somatic cells interactions, meiotic resumption, cytoskeletal dynamics and cytoplasmic reorganization. Hum Reprod Update. 2015;21(4):427-54. https://doi.org/10. 1093/humupd/dmv011.

3. Dean J. Exacting requirements for development of the egg. N Engl J Med. 2016:374(3):279-80. https://doi.org/10.1056/NEJMe1515512.

4. Huang HL, Lv C, Zhao YC, Li W, He XM, Li P, Sha AG, Tian X, Papasian CJ, Deng HW, Lu GX, Xiao HM. Mutant ZP1 in familial infertility. N Engl J Med. 2014:370(13):1220-6. https://doi.org/10.1056/NEJMoa1308851.

5. Dai C, Hu L, Gong F, Tan Y, Cai S, Zhang S, Dai J, Lu C, Chen J, Chen Y, Lu G, Du J, Lin G. ZP2 pathogenic variants cause in vitro fertilization failure and female infertility. Genet Med. 2018. https://doi.org/10.1038/s41436-018-0064-y.
6. Chen B, Li B, Li D, Yan Z, Mao X, Xu Y, Mu J, Li Q, Jin L, He L, Kuang Y, Sang Q, Wang L. Novel mutations and structural deletions in TUBB8: expanding mutational and phenotypic spectrum of patients with arrest in oocyte maturation, fertilization or early embryonic development. Hum Reprod. 2017;32(2):457-64. https://doi.org/10.1093/humrep/dew322.

7. Sang Q, Li B, Kuang Y, Wang X, Zhang Z, Chen B, Wu L, Lyu Q, Fu Y, Yan Z, Mao X, Xu Y, Mu J, Li Q, Jin L, He L, Wang L. Homozygous mutations in WEE2 cause fertilization failure and female infertility. Am J Hum Genet. 2018; 102(4):649-57. https://doi.org/10.1016/j.ajhg.2018.02.015.

8. Chen B, Zhang Z, Sun X, Kuang Y, Mao X, Wang X, Yan Z, Li B, Xu Y, Yu M, Fu J, Mu J, Zhou Z, Li Q, Jin L, He L, Sang Q, Wang L. Biallelic mutations in PATL2 cause female infertility characterized by oocyte maturation arrest. Am J Hum Genet. 2017;101(4):609-15. https://doi.org/10.1016/j.ajhg.2017.08.018.

9. Feng R, Sang Q, Kuang Y, Sun X, Yan Z, Zhang S, Shi J, Tian G, Luchniak A, Fukuda Y, Li B, Yu M, Chen J, Xu Y, Guo L, Qu R, Wang X, Sun Z, Liu M, Shi $H$, Wang $H$, Feng $Y$, Shao R, Chai R, Li Q, Xing Q, Zhang R, Nogales E, Jin L, He L, Gupta ML Jr, Cowan NJ, Wang L. Mutations in TUBB8 and human oocyte meiotic arrest. N Engl J Med. 2016;374(3):223-32. https://doi.org/10. 1056/NEJMoa1510791.

10. Feng $R$, Yan Z, Li B, Yu M, Sang Q, Tian G, Xu Y, Chen B, Qu R, Sun Z, Sun X, Jin L, He L, Kuang Y, Cowan NJ, Wang L. Mutations in TUBB8 cause a multiplicity of phenotypes in human oocytes and early embryos. J Med Genet. 2016;53(10):662-71. https://doi.org/10.1136/jmedgenet-2016-103891.

11. Online mendelian inheritance in man. https://www.omim.org/. Accessed 22 Dec 2019.

12. PubMed http//www ncbi.nlm.nih.gov/pubmed/. Accessed 22 De 2019.

13. Gene Ontology. http://geneontology.org/. Accessed 22 Dec 2019.

14. Mouse genome informatics.

15. Chen T, Bian Y, Liu X, Zhao S, Wu K, Yan L, Li M, Yang Z, Liu H, Zhao H, Chen $Z J$. A recurrent missense mutation in ZP3 causes empty follicle syndrome and female infertility. Am J Hum Genet. 2017;101(3):459-65. https://doi.org/10.1016/j.ajhg.2017.08.001.

16. Chen B, Wang W, Peng $X$, Jiang H, Zhang S, Li D, Li B, Fu J, Kuang Y, Sun $X$, Wang X, Zhang Z, Wu L, Zhou Z, Lyu Q, Yan Z, Mao X, Xu Y, Mu J, Li Q, Jin $L$, He L, Sang Q, Wang L. The comprehensive mutational and phenotypic spectrum of TUBB8 in female infertility. Eur J Hum Genet. 2019;27(2):300-7. https://doi.org/10.1038/s41431-018-0283-3.

17. Sirajuddin M, Rice LM, Vale RD. Regulation of microtubule motors by tubulin isotypes and post-translational modifications. Nat Cell Biol. 2014;16(4):33544. https://doi.org/10.1038/ncb2920

18. Janke $C$. The tubulin code: molecular components, readout mechanisms, and functions. J Cell Biol. 2014;206(4):461-72. https://doi.org/10.1083/jcb. 201406055.

19. Huang $L$, Tong $X$, Luo L, Zheng S, Jin R, Fu Y, Zhou G, Li D, Liu Y. Mutation analysis of the TUBB8 gene in nine infertile women with oocyte maturation arrest. Reprod BioMed Online. 2017;35(3):305-10. https://doi.org/10.1016/j. rbmo.2017.05.017.

20. Wang AC, Zhang YS, Wang BS, Zhao XY, Wu FX, Zhai XH, Sun JX, Mei SY. Mutation analysis of the TUBB8 gene in primary infertile women with arrest in oocyte maturation. Gynecol Endocrinol. 2018;34(10):900-4. https://doi. org/10.1080/09513590.2018.1464138.

21. Xiang J, Wang W, Qian C, Xue J, Wang T, Li H, Li H. Human oocyte maturation arrest caused by a novel missense mutation in TUBB8. J Int Med Res. 2018;46(9):3759-64. https://doi.org/10.1177/0300060518778638.

22. Yuan $\mathrm{P}$, Zheng L, Liang H, Li Y, Zhao H, Li R, Lai L, Zhang Q, Wang W. A novel mutation in the TUBB8 gene is associated with complete cleavage failure in fertilized eggs. J Assist Reprod Genet. 2018;35(7):1349-56. https:// doi.org/10.1007/s10815-018-1188-3.

\section{Publisher's Note}

Springer Nature remains neutral with regard to jurisdictional claims in published maps and institutional affiliations. 